\title{
High chemoselectivity in the phenol synthesis
}

\author{
Matthias Rudolph ${ }^{1}$, Melissa Q. McCreery², Wolfgang Frey ${ }^{2}$ \\ and A. Stephen K. Hashmi ${ }^{*} 1,2$
}

\author{
Full Research Paper \\ Address: \\ ${ }^{1}$ Organisch-Chemisches Institut, Ruprecht-Karls-Universität \\ Heidelberg, Im Neuenheimer Feld 270, 69120 Heidelberg, Germany \\ and ${ }^{2}$ Institut für Organische Chemie, Universität Stuttgart, \\ Pfaffenwaldring 55, 70569 Stuttgart, Germany \\ Email: \\ A. Stephen K. Hashmi* - hashmi@hashmi.de \\ * Corresponding author \\ Keywords: \\ alcohols; alkenes; alkynes; furans; gold; ketones
}

\author{
Beilstein J. Org. Chem. 2011, 7, 794-801. \\ doi:10.3762/bjoc. 7.90 \\ Received: 01 April 2011 \\ Accepted: 23 May 2011 \\ Published: 10 June 2011 \\ Guest Editor: F. D. Toste \\ (C) 2011 Rudolph et al; licensee Beilstein-Institut. \\ License and terms: see end of document.
}

\begin{abstract}
Efforts to trap early intermediates of the gold-catalyzed phenol synthesis failed. Neither inter- nor intramolecularly offered vinyl groups, ketones or alcohols were able to intercept the gold carbenoid species. This indicates that the competing steps of the goldcatalyzed phenol synthesis are much faster than the steps of the interception reaction. In the latter the barrier of activation is higher. At the same time this explains the high tolerance of this very efficient and general reaction towards functional groups.
\end{abstract}

\section{Introduction}

As documented in numerous reviews [1-10], over the last eleven years homogeneous gold catalysis has emerged from early examples $[11,12]$ which documented its potential for organic synthesis of even complex molecules to an established tool in preparative organic chemistry $[13,14]$. One of these early examples is the gold-catalyzed phenol synthesis [12] in which the furan-ynes 1 used as substrates represent the first ene-ynetype compounds ever used in gold catalysis. While many investigations in the field focused on methodology, mechanistic research was much less widespread $[2,3,15]$. The goldcatalyzed ene-yne cycloisomerization reactions are, mechanistically, very complex reactions [16-18], and the furan-yne cycloisomerization is no exception. For the latter reaction arene oxides D [19] and oxepines C [20] could be detected as intermediates, and these could even be trapped by Diels-Alder reactions. In addition, labelling studies were carried out and the electronic influence of substituents was investigated [21]. Computational studies as well as side-products produced in the reaction pointed towards intermediates $\mathbf{A}$ and $\mathbf{B}$ (Scheme 1) [22-25]. Moreover, interesting new pathways were opened when ynamides and alkynyl ether substrates were employed: Here $\mathbf{A}$ is also a possible intermediate along these pathways [25].

Since direct experimental evidence existed only for $\mathbf{C}$ and $\mathbf{D}$, we intended to intercept the postulated carbenoid intermediates 


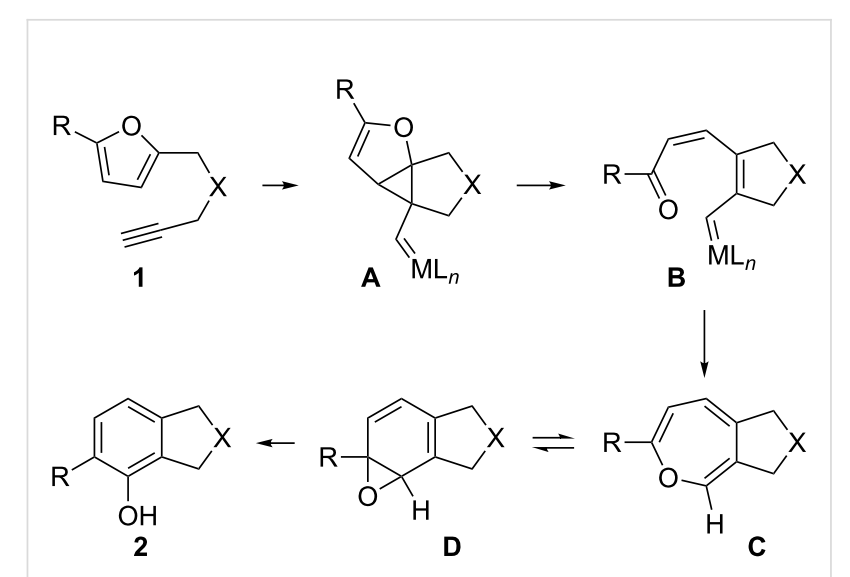

Scheme 1: Mechanism of the furan-yne reaction.

A or B. Apart from intermolecular trapping [26-33], intramolecular trapping of such carbenoids has also been reported [34]. One option would be to offer a competing carbonyl group, to produce a carbonyl ylide, which could then undergo a 1,3dipolar cycloaddition [35]. The second option would be a classical cyclopropanation of an olefin. A third option would be trapping of intermediate A with an intramolecular hydroxy nucleophile [36]. Here we report our observations when trying to apply these principles to intermediates of type $\mathbf{A}$ or $\mathbf{B}$.

\section{Results and Discussion Intermolecular olefinic trapping reagents}

We started with the simplest experiments, namely the intermolecular trapping of the gold carbenoid intermediates. When 3 was reacted in the presence of an activated olefin, such as norbornene or styrene, phenol $\mathbf{4}$ was formed exclusively in essentially quantitative yield, no other products could be detected (Scheme 2).

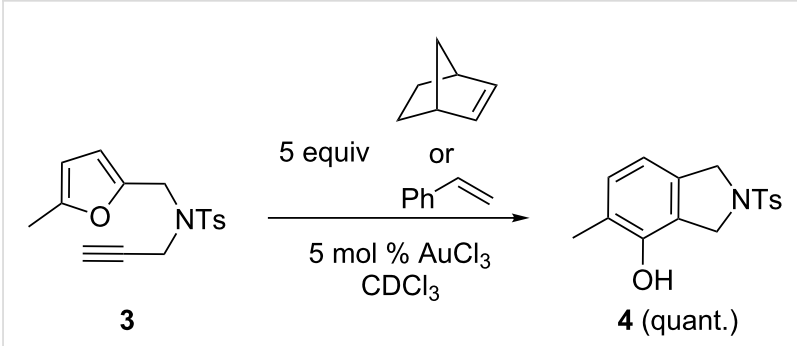

Scheme 2: Efforts for intermolecular trapping with olefins failed.

Experiments with a competing carbonyl group (competing with the carbonyl group in intermediate B) were also unsuccessful. Ketone 5 [37], prepared by the addition of methyllithium to commercially available hex-5-enoic acid, was used as an external carbonyl group. Reaction with both tosylamide 3 and ether 6 always delivered the phenolic products 4 or 7 , respectively (Scheme 3). The same result was obtained when $\mathrm{PtCl}_{2}$ was used as the catalyst for the conversion of $\mathbf{3}$.

\section{Intramolecular olefinic trapping reagents}

The next step was to offer the styrene unit in an intramolecular manner. Substrate 8 could potentially undergo three different modes of reaction (Scheme 4). After the initial step, the intermediate $\mathbf{E}$ would be produced (analogous to $\mathbf{A}$ ). Cyclopropanation of the styrene subunit by the cyclopropyl carbenoid would deliver 9. If $\mathbf{E}$ rearranged to the vinylcarbenoid $\mathbf{F}$, the two competing reactions would be the formation of the phenol $\mathbf{1 0}$ and cyclopropanation to form $\mathbf{1 1 .}$

The synthesis of $\mathbf{8}$ was possible by a short route (Scheme 5). Starting from the commercially available 2-bromostyrene (12), a halogen-metal exchange and subsequent formylation according to a procedure of Fukumoto et al. [38] gave 13. Add-<smiles>C#CC[NH+]([SH2+])Cc1ccc(C)o1</smiles><smiles>C#CCOCc1ccc(-c2ccc(Br)cc2)o1</smiles><smiles></smiles><smiles>Oc1c(-c2ccc(Br)cc2)ccc2c1C[NH+]([SH3+])C2</smiles> 


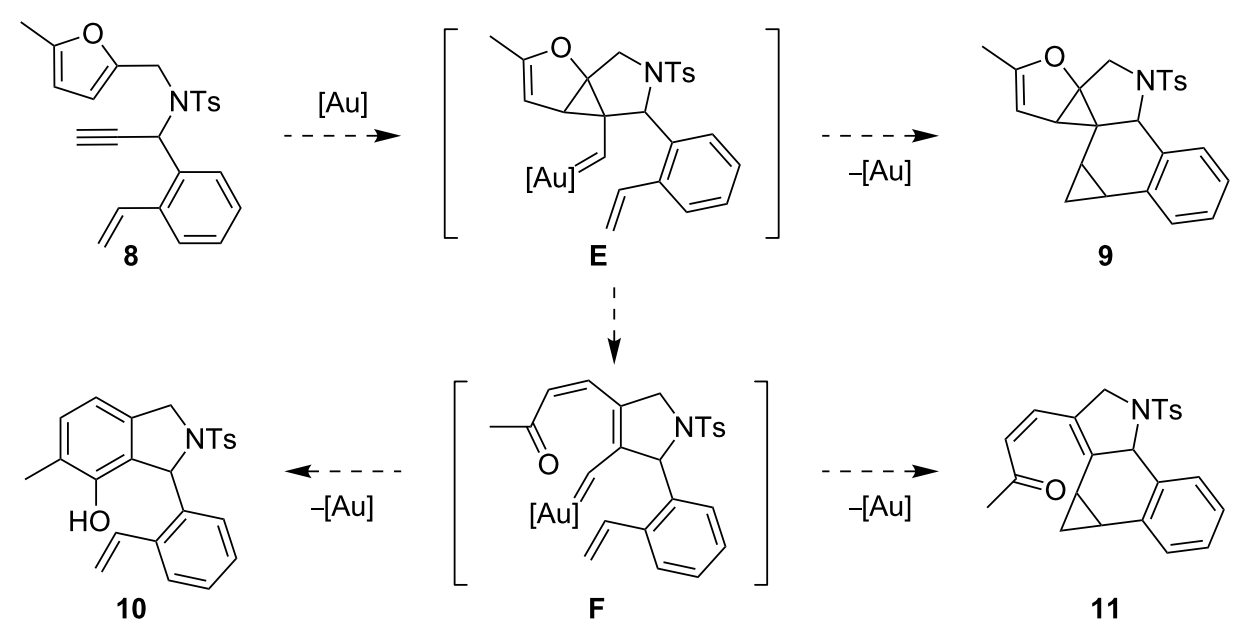

Scheme 4: Potential products of an intramolecular trapping experiment with substrate 8.<smiles>C=Cc1ccccc1Br</smiles>

12

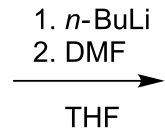

$\mathrm{THF}$

$8(32 \%)$<smiles>C=Cc1ccccc1C=O</smiles>

$13(77 \%)$

$$
\downarrow \frac{\overline{\text { THF }}}{\bar{\equiv}} \mathrm{MgBr}
$$<smiles>C#CC(O)c1ccccc1C=C</smiles>

$14(96 \%)$
Scheme 5: Synthesis of the substrate 8.

ition of ethynylmagnesium bromide to $\mathbf{1 3}$ led to $\mathbf{1 4}$, which reacted with furan 15 [40] under Mitsunobu conditions [39] to afford 8. While the yields were good for the first two steps of the reaction sequence, the yield of the last step was only $32 \%$.

With $\mathrm{AuCl}_{3}$ the phenol $\mathbf{1 0}$ was formed exclusively (Scheme 6). The structure was unambiguously confirmed by X-ray crystal structure analysis (Figure 1). It shows an interesting hydrogen bond-like interaction of the phenolic hydroxy group and the alkene unit. After changing the solvent from acetonitrile to $\mathrm{CDCl}_{3}$, and the gold(I) catalyst to [Mes $3{ }_{3} \mathrm{PAu}_{\mathrm{NTf}}$ [41], only $\mathbf{1 0}$ was again observed. Thus, neither of the two oxidation states of the gold catalyst gave any product derived from the intercepted intermediate (the solvent was changed to $\mathrm{CDCl}_{3}$ since the activity of gold(I) is significantly reduced by $\mathrm{MeCN}$ ).

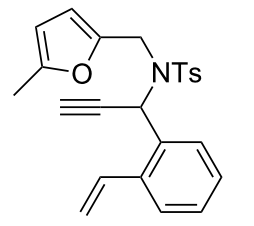

8
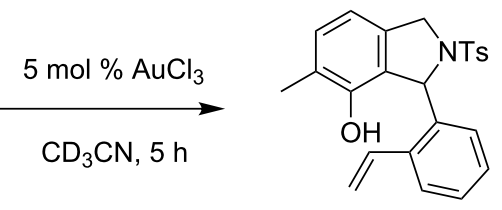

$10(75 \%)$
Scheme 6: With substrate 8 the product of the phenol synthesis was exclusively obtained.

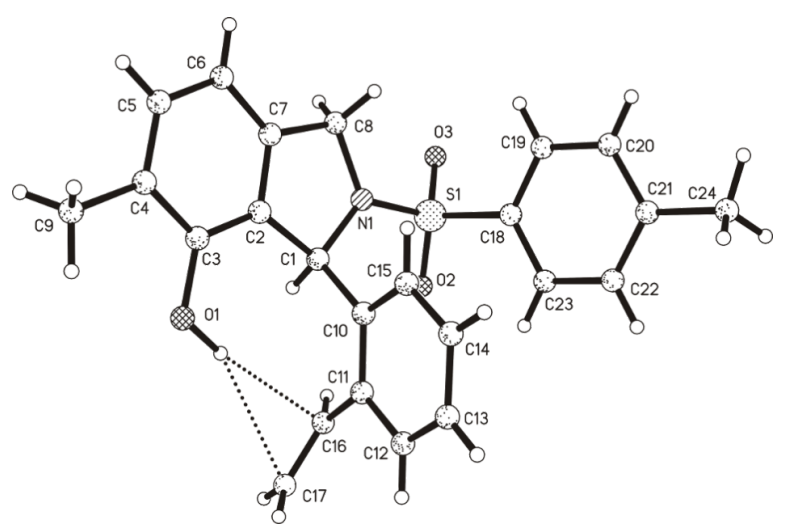

Figure 1: Solid-state molecular structure of 10.

\section{Intramolecular ketone as potential trapping reagent}

Next we decided to use a carbonyl group as the competing unit. The intermediate $\mathbf{G}$, formed from substrate $\mathbf{1 6}$, would offer the option of competition of the phenol synthesis (Scheme 7, pathway a) to yield 18, and reaction with the second carbonyl group (Scheme 7, pathway b). The latter would form intermedi- 


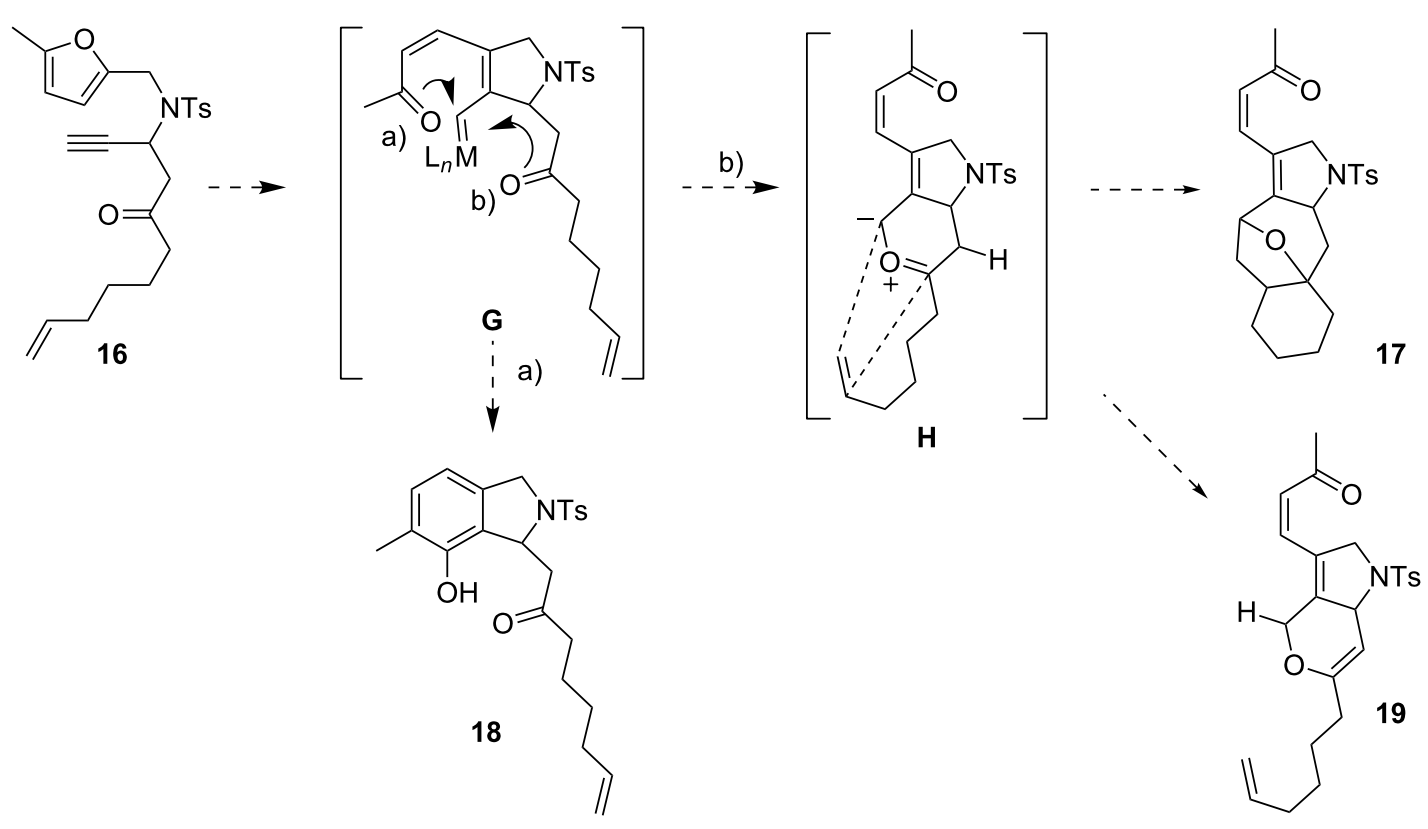

Scheme 7: Potential products of an intramolecular trapping experiment with substrate 16

ate $\mathbf{H}$, which could then either afford product $\mathbf{1 7}$ via intramolecular 1,3-dipolar cycloaddition with the olefin, or could form the diene 19 by proton migration.

The synthesis of $\mathbf{1 6}$ was only possible by a 9 -step sequence (Scheme 8). The starting point was a Claisen condensation of ester $\mathbf{2 0}$ and tert-butyl acetate (21) in the presence of lithium hexamethyldisilazide as the base. Ketoester $\mathbf{2 2}$ was obtained in $56 \%$ yield, however, the two-fold addition of $\mathbf{2 1}$ could not be suppressed completely and $14 \%$ of the corresponding tertiary alcohol 30 was also obtained. Reduction of the ketone 22 with sodium borohydride and protection of the alcohol 23 with tertbutyldimethylsilylchloride delivered $\mathbf{2 4}$ in excellent yield. Reduction of the ester group with diisobutylaluminiumhydride gave aldehyde $\mathbf{2 5}$. The addition of lithiated trimethylsilylacetylene provided the propargylic alcohol $\mathbf{2 6}$ and reaction with $\mathbf{1 5}$ under Mitsunobu conditions yielded 27. Deprotection of the alkyne $\mathbf{2 7}$ and the silyl ether $\mathbf{2 8}$, followed by the oxidation of the resulting alcohol $\mathbf{2 9}$ finally led to $\mathbf{1 6}$. It was not possible to remove both silyl groups simultaneously with TBAF, longer reaction times which would be necessary for the deprotection of the hydroxy group led to decomposition of the substrate. At $0{ }^{\circ} \mathrm{C}$ and with a very short reaction time, the alkyne was deprotected selectively. Selective deprotection of the alcohol was then possible with a mixture of acetic acid/water/THF. Another route, in which the alcohol function was deprotected first, then oxidized, followed by removal of the trimethylsilyl group from the alkyne also failed. Thus treatment of $\mathbf{2 7}$ with acetic acid in aqueous THF gave the desired alcohol 31 in quantitative yield. However, whilst Ley oxidation [42] on the small-scale delivered ketone $\mathbf{3 2}$ in yields of up to $80 \%$, on a larger scale the yield of 32 dropped dramatically to $28 \%$ and was accompanied by two side-products, $\mathbf{3 3}$ and $\mathbf{5}$. The latter are formed by an elimination reaction of the amide in $\mathbf{3 2}$. Furthermore, it was not possible to deprotect ketone $\mathbf{3 2}$ due to rapid decomposition.

One of the diastereoisomers of $\mathbf{2 8}$ was identified as the anti-product 28a by an X-ray crystal structure analysis (Figure 2).

The conversion of $\mathbf{1 6}$ with $5 \mathrm{~mol} \% \mathrm{AuCl}_{3}$ proceeded fast and gave exclusively phenol 18. No other products could be detected (Scheme 9).

The two gold(III) complexes 34 [43] and 35 [37] as well as the dinuclear gold(I) complex 36 [44] gave the same result (Figure 3). When the catalyst was changed to platinum(II) chloride in acetone, a complex mixture of inseparable products was obtained.

Since the two diastereoisomers $\mathbf{2 8 a}$ and $\mathbf{2 8 b}$ with the propargylic stereocenters were separable, we investigated the goldcatalyzed conversion of the pure isomers. From the NMR 


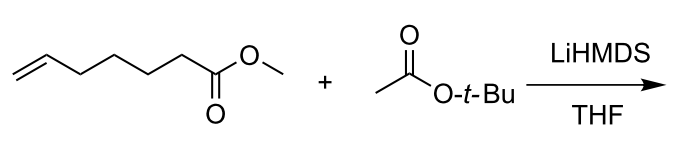

20

21<smiles>C=CCCCCC(O)(CC(=O)OCCCC)CC(=O)OC(C)(C)C</smiles>

$30(14 \%)$<smiles>C=CCCCCC(=O)CC(=O)OC(C)(C)C</smiles>

22 (56\%) $\mathrm{NaBH}_{4}, \mathrm{MeOH}$

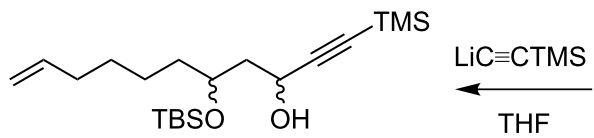

26 (95\%)

$\mathrm{PPh}_{3}, \mathrm{DEAD}, \mathrm{THF}$
$\mathrm{NHTS}$

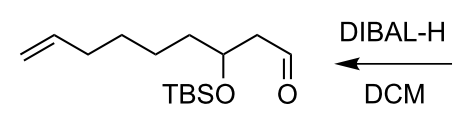

$25(83 \%)$

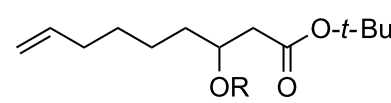

23: $\mathrm{R}=\mathrm{H}(96 \%) \quad \square$ TBSCl,

24: $R=$ TBS $(96 \%) \longleftarrow$ THF

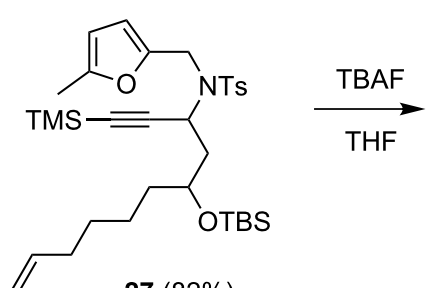

$27(82 \%)$

HOAc, $\mathrm{THF} / \mathrm{H}_{2} \mathrm{O}$

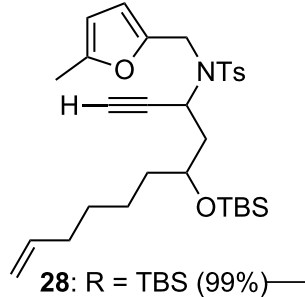

28: $R=$ TBS $(99 \%)$

29: $R=H(92 \%)$

HOAC, $\mathrm{THF} / \mathrm{H}_{2} \mathrm{O}$

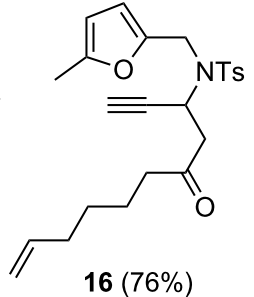

$16(76 \%)$
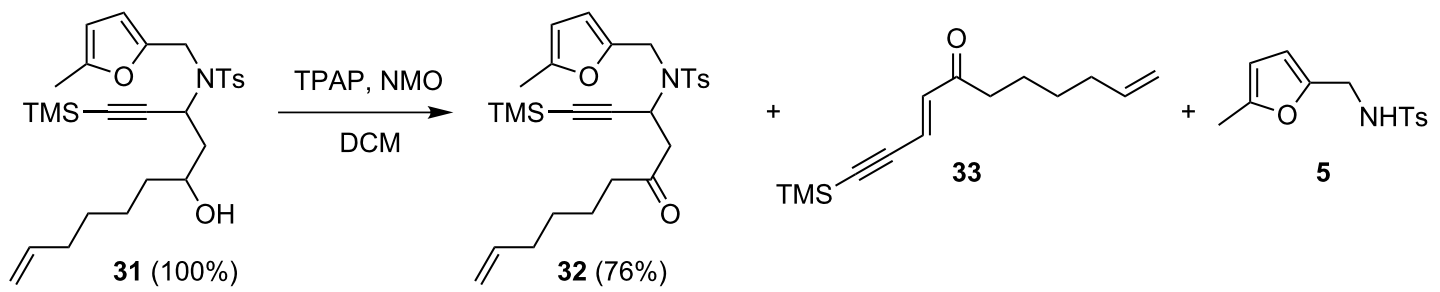

$\neq$ decomposition with TBAF or $\mathrm{K}_{2} \mathrm{CO}_{3} / \mathrm{MeOH}$

16

Scheme 8: Synthesis of the substrate 16.

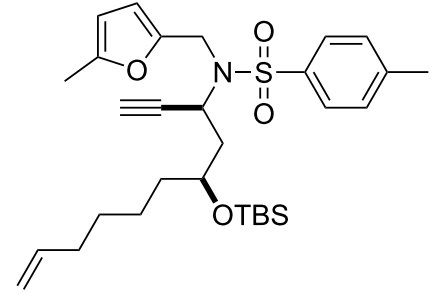

$28 a$

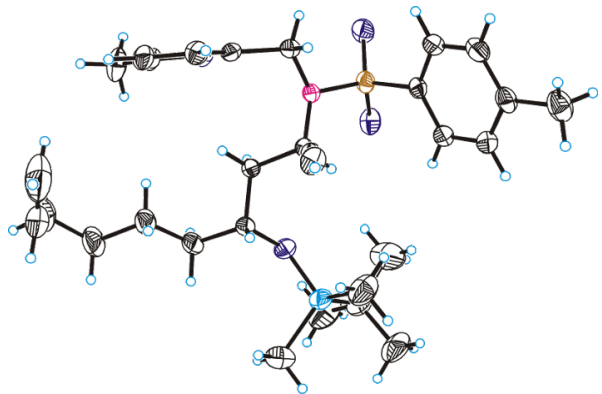

Figure 2: Solid-state molecular structure of $\mathbf{2 8 a}$. 

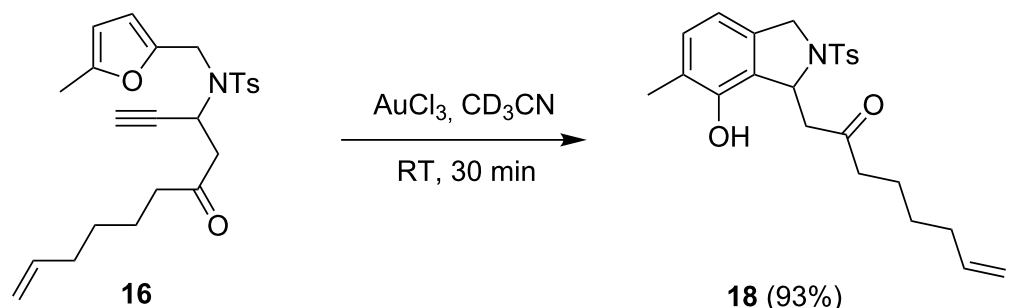

$18(93 \%)$

Scheme 9: With substrate 16 the product of the phenol synthesis is obtained exclusively.<smiles></smiles>

Cl<smiles></smiles>

35
$\left[\left(\mathrm{Mes}_{3} \mathrm{PAu}\right)_{2} \mathrm{Cl}_{\mathrm{BF}}\right.$

36
Figure 3: Catalysts 34,35 and 36 .

spectra taken during the conversion (Figure 4), it could be clearly seen that no epimerization of the propargylic position occurred. In addition to the selective transformation to the phenols $37 \mathbf{a}$ and $\mathbf{3 7} \mathbf{b}$ as the main reaction products, partial removal of the TBS group was observed (38, Figure 5).

\section{Intramolecular alcohol as potential trapping reagent}

For the interception of intermediate $\mathbf{A}$ we also considered the option of an intramolecular hydroxy nucleophile, compound 39 (Scheme 10) would represent this type of substrate. The intermediate I would be an analogue of A. Instead of the phenol syn-

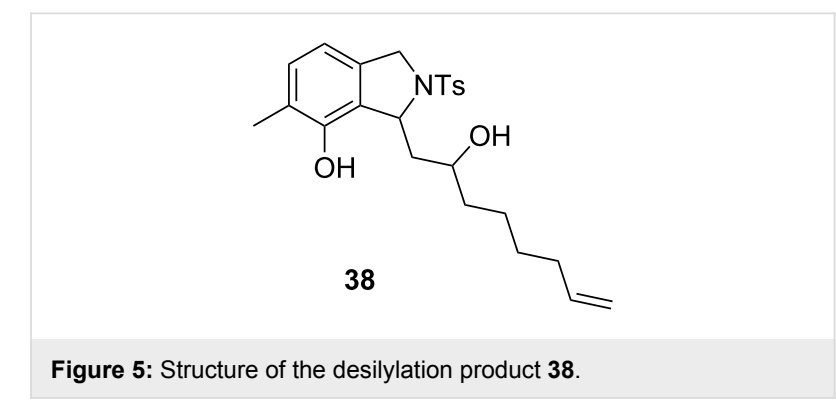

thesis to yield $\mathbf{4 0}$, an intramolecular nucleophilic attack at the activated three-membered ring could form intermediate $\mathbf{J}$, which, after protodeauration, would provide ketal 41.

The synthesis of $\mathbf{3 9}$ was readily accomplished by the addition of lithiated sylvan $\mathbf{4 2}$ to the PMB-protected aldehyde $\mathbf{4 3}$ (Scheme 11) [45]. The resulting furfuryl alcohol 44 was then propargylated to give $\mathbf{4 5}$. The deprotection was however, problematic. Treatment of the latter with cerium ammonium nitrate led to decomposition. Only with DDQ was the desired alcohol 39 obtained in moderate yield.
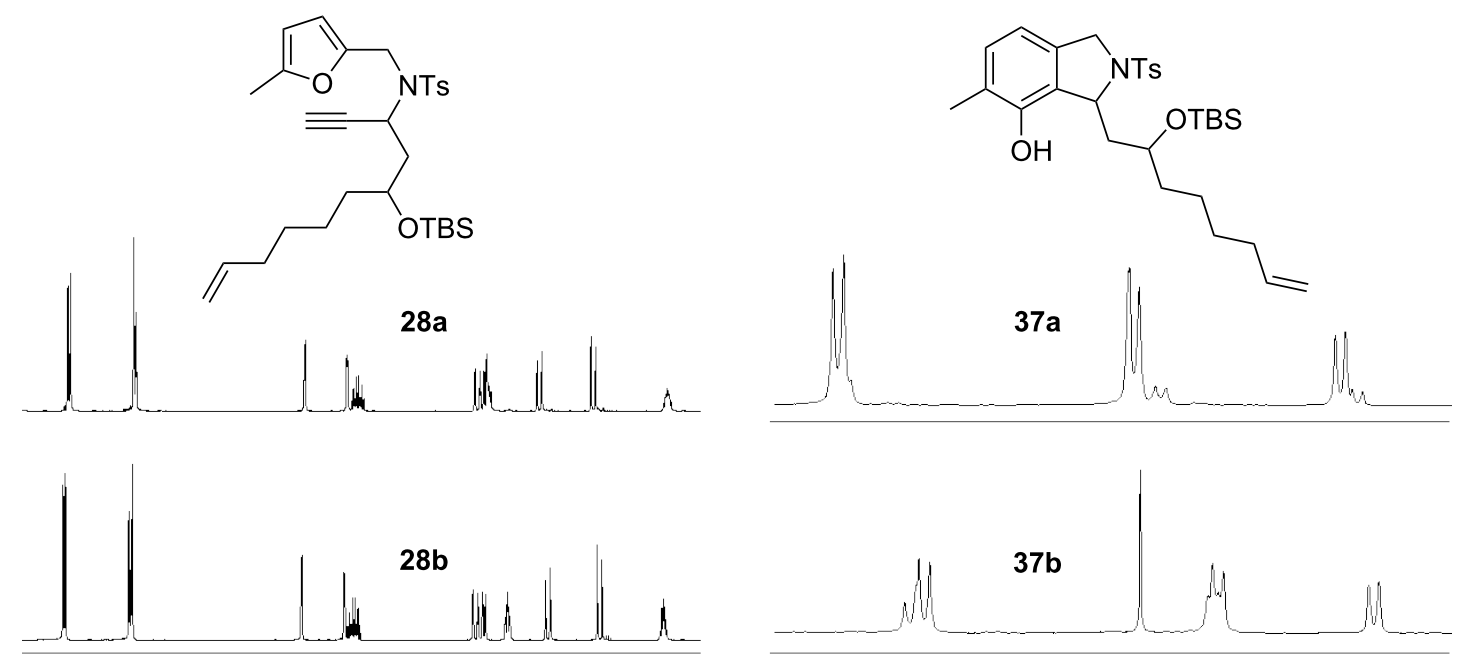

Figure 4: ${ }^{1} \mathrm{H}$ NMR spectra of the separated diastereoisomers of the substrates for catalysis $\mathbf{2 8}$ (left) and of the products $\mathbf{3 7}$ (right, the small signals are due to the deprotected compounds 38 ). 


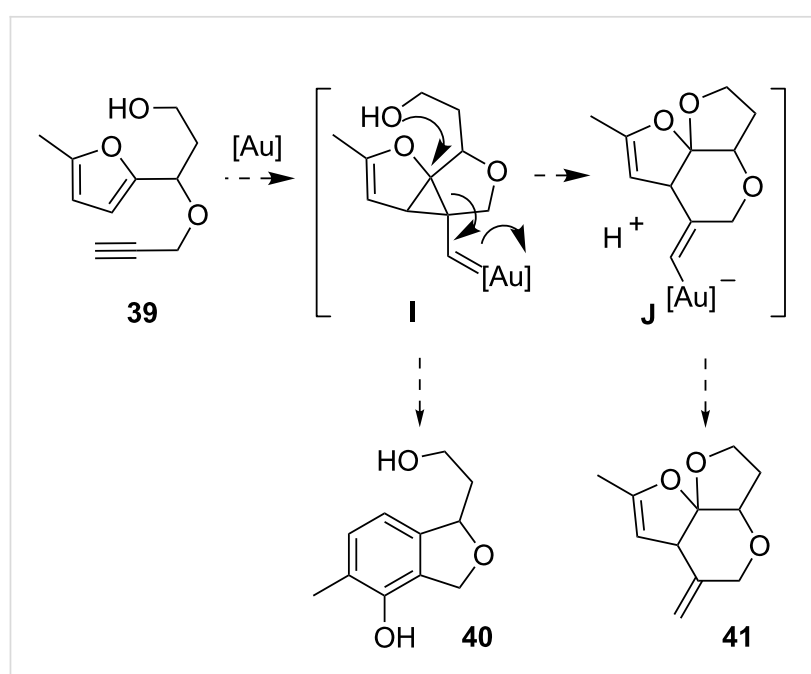

Scheme 10: Potential products of an intramolecular trapping experiment with substrate 39 .

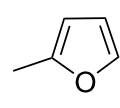

42

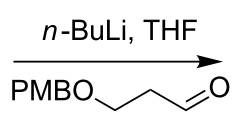

43

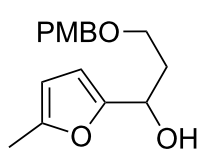

$44(82 \%)$

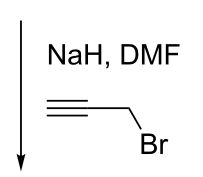

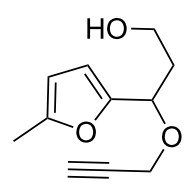

$39(65 \%)$
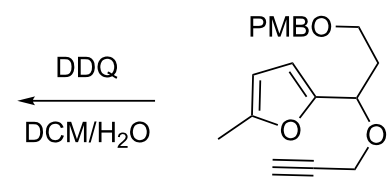

$45(90 \%)$
Scheme 11: Synthesis of the substrate 39.

The conversion of $\mathbf{3 9}$, catalyzed by $\mathrm{AuCl}_{3}$ in $\mathrm{CDCl}_{3}$, again only produced the expected phenol 40 (Scheme 12). Not unexpectedly, the PMB-protected alcohol $\mathbf{4 5}$ was similarly converted to 46. $\mathrm{PtCl}_{2}$ did not lead to a change in selectivity.

\section{Conclusion}

The complete failure of both the inter- and the intramolecular trapping experiments shows that the gold-catalyzed phenol synthesis follows a reaction pathway low in energy. These observations also nicely explain the high functional group tolerance, for example, towards olefins and alcohols.

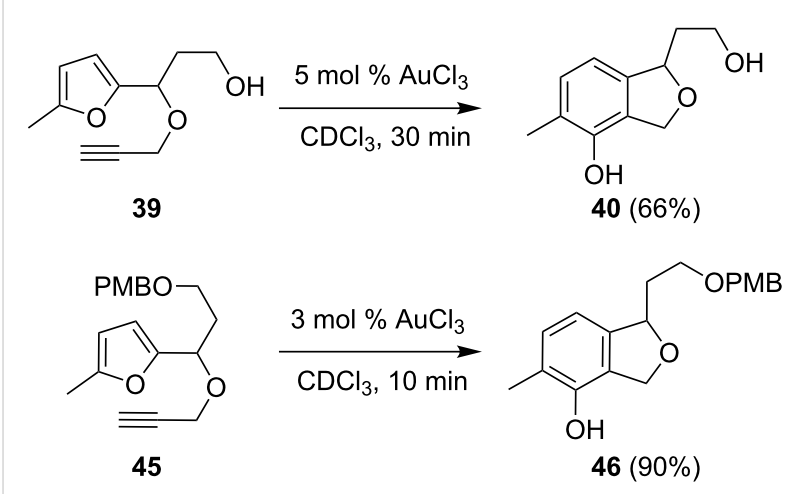

Scheme 12: With substrate $\mathbf{3 9}$ and $\mathbf{4 5}$ exclusively the product of the phenol synthesis is obtained.

\section{Supporting Information}

\section{Supporting Information File 1}

Experimental details and characterization data of synthesized compounds.

[http://www.beilstein-journals.org/bjoc/content/ supplementary/1860-5397-7-90-S1.pdf]

\section{Acknowledgements}

This work was generously supported by the Deutsche Forschungsgemeinschaft (SFB 623) and by Umicore AG \& Co. KG.

\section{References}

1. Hashmi, A. S. K.; Hutchings, G. J. Angew. Chem. 2006, 118, 8064-8105. doi:10.1002/ange.200602454

Angew. Chem., Int. Ed. 2006, 45, 7896-7936.

doi:10.1002/anie.200602454

2. Gorin, D. J.; Toste, F. D. Nature 2007, 446, 395-403. doi:10.1038/nature05592

3. Fürstner, A.; Davies, P. W. Angew. Chem. 2007, 119, 3478-3519. doi:10.1002/ange.200604335

Angew. Chem., Int. Ed. 2007, 46, 3410-3449.

doi:10.1002/anie.200604335

4. Jiménez-Núñez, E.; Echavarren, A. M. Chem. Commun. 2007, 333-346. doi:10.1039/b612008c

5. Li, Z.; Brouwer, C.; He, C. Chem. Rev. 2008, 108, 3239-3265. doi:10.1021/cr068434I

6. Arcadi, A. Chem. Rev. 2008, 108, 3266-3325. doi:10.1021/cr068435d

7. Muzart, J. Tetrahedron 2008, 64, 5815-5849. doi:10.1016/j.tet.2008.04.018

8. Shen, H. C. Tetrahedron 2008, 64, 7847-7870. doi:10.1016/j.tet.2008.05.082

9. Hashmi, A. S. K.; Bührle, M. Aldrichimica Acta 2010, 43, 27-33.

10. Krause, N.; Winter, C. Chem. Rev. 2011, 111, 1994-2009. doi:10.1021/cr1004088 
11. Hashmi, A. S. K.; Schwarz, L.; Choi, J.-H.; Frost, T. M. Angew. Chem. 2000, 112, 2382-2385.

doi:10.1002/1521-3757(20000703)112:13<2382::AID-ANGE2382>3.0. $\mathrm{CO} ; 2-\mathrm{R}$

Angew. Chem., Int. Ed. 2000, 39, 2285-2288.

doi:10.1002/1521-3773(20000703)39:13<2285::AID-ANIE2285>3.0.CO ;2-F

12. Hashmi, A. S. K.; Frost, T. M.; Bats, J. W. J. Am. Chem. Soc. 2000, 122, 11553-11554. doi:10.1021/ja005570d

13. Hashmi, A. S. K.; Rudolph, M. Chem. Soc. Rev. 2008, 37, 1766-1775. doi:10.1039/b615629k

14. Fürstner, A. Chem. Soc. Rev. 2009, 38, 3208-3221. doi:10.1039/b816696j

15. Hashmi, A. S. K. Angew. Chem. 2010, 122, 5360-5369.

doi:10.1002/ange.200907078

Angew. Chem., Int. Ed. 2010, 49, 5232-5241.

doi:10.1002/anie.200907078

16. Nieto-Oberhuber, C.; López, S.; Jiménez-Núñez, E.; Echavarren, A. M. Chem.-Eur. J. 2006, 12, 5916-5923. doi:10.1002/chem.200600174

17. Dudnik, A. S.; Chernyak, N.; Gevorgyan, V. Aldrichimica Acta 2010, 43, 37-46.

18. Belmont, P.; Parker, E. Eur. J. Org. Chem. 2009, 6075-6089. doi:10.1002/ejoc.200900790

19. Hashmi, A. S. K.; Rudolph, M.; Weyrauch, J. P.; Wölfle, M.; Frey, W.; Bats, J. W. Angew. Chem. 2005, 117, 2858-2861. doi:10.1002/ange.200462672

Angew. Chem., Int. Ed. 2005, 44, 2798-2801. doi:10.1002/anie.200462672

20. Hashmi, A. S. K.; Kurpejović, E.; Wölfle, M.; Frey, W.; Bats, J. W. Adv. Synth. Catal. 2007, 349, 1743-1750. doi:10.1002/adsc.200600653

21. Hashmi, A. S. K.; Rudolph, M.; Siehl, H.-U.; Tanaka, M.; Bats, J. W.; Frey, W. Chem.-Eur. J. 2008, 14, 3703-3708. doi:10.1002/chem.200701795

22. Martín-Matute, B.; Cárdenas, D. J.; Echavarren, A. M. Angew. Chem. 2001, 113, 4890-4893. doi:10.1002/1521-3757(20011217)113:24<4890::AID-ANGE4890>3.0. CO;2-V Angew. Chem., Int. Ed. 2001, 40, 4754-4757. doi:10.1002/1521-3773(20011217)40:24<4754::AID-ANIE4754>3.0.CO ;2-9

23. Martín-Matute, B.; Nevado, C.; Cárdenas, D. J.; Echavarren, A. M. J. Am. Chem. Soc. 2003, 125, 5757-5766. doi:10.1021/ja029125p

24. Hashmi, A. S. K.; Wölfle, M.; Ata, F.; Hamzic, M.; Salathé, R.; Frey, W. Adv. Synth. Catal. 2006, 348, 2501-2508. doi:10.1002/adsc.200600367

25. Hashmi, A. S. K. Pure Appl. Chem. 2010, 82, 1517-1528. doi:10.1351/PAC-CON-09-10-34

26. Miki, K.; Ohe, K.; Uemura, S. Tetrahedron Lett. 2003, 44, 2019-2022. doi:10.1016/S0040-4039(03)00219-3

27. Miki, K.; Ohe, K.; Uemura, S. J. Org. Chem. 2003, 68, 8505-8513. doi:10.1021/jo034841a

28. Johansson, M. J.; Gorin, D. J.; Staben, S. T.; Toste, F. D. J. Am. Chem. Soc. 2005, 127, 18002-18003. doi:10.1021/ja0552500

29. Mamane, V.; Gress, T.; Krause, H.; Fürstner, A. J. Am. Chem. Soc. 2004, 126, 8654-8655. doi:10.1021/ja048094q

30. Fürstner, A.; Hannen, P. Chem. Commun. 2004, 2546-2547. doi:10.1039/b412354a

31. Fürstner, A.; Hannen, P. Chem.-Eur. J. 2006, 12, 3006-3019. doi:10.1002/chem.200501299
32. Fehr, C.; Galindo, J. Angew. Chem. 2006, 118, 2967-2970. doi:10.1002/ange.200504543

Angew. Chem., Int. Ed. 2006, 45, 2901-2904. doi:10.1002/anie.200504543

33. Nieto-Oberhuber, C.; López, S.; Muňoz, M. P.; Jiménez-Núñez, E.; Buñuel, E.; Cárdenas, D. J.; Echavarren, A. M. Chem.-Eur. J. 2006, 12, 1694-1702. doi:10.1002/chem.200501089

34. López, S.; Herrero-Gómez, E.; Pérez-Galán, P.; Nieto-Oberhuber, C.; Echavarren, A. M. Angew. Chem. 2006, 118, 6175-6178. doi:10.1002/ange. 200602448 Angew. Chem., Int. Ed. 2006, 45, 6029-6032. doi:10.1002/anie.200602448

35. Padwa, A.; Curtis, E. A.; Sandanayaka, V. P. J. Org. Chem. 1996, 61, 73-81. doi:10.1021/jo951371e

36. Zhang, L.; Kozmin, S. A. J. Am. Chem. Soc. 2005, 127, 6962-6963. doi:10.1021/ja051110e

37. Rubottom, G. M.; Kim, C. J. Org. Chem. 1983, 48, 1550-1552. doi:10.1021/jo00157a038

38. Hibino, S.; Sugino, E.; Adachi, Y.; Nomi, K.; Sato, K.; Fukumoto, K. Heterocycles 1989, 28, 275-282. doi:10.3987/COM-88-S12

39. Mitsunobu, O.; Kato, K.; Tomari, M. Tetrahedron 1970, 26, 5731-5736. doi:10.1016/0040-4020(70)80009-6

40. Carrettin, S.; Blanco, M. C.; Corma, A.; Hashmi, A. S. K. Adv. Synth. Catal. 2006, 348, 1283-1288. doi:10.1002/adsc.200606099

41. Blanco, M. C. AURICAT EU-RTN final report, Universität Stuttgart, 2006.

42. Ley, S. V.; Norman, J.; Griffith, W. P.; Marsden, S. P. Synthesis 1994, 639-666. doi:10.1055/s-1994-25538

43. Canovese, L.; Cattalini, L.; Marangoni, G.; Tobe, M. L. J. Chem. Soc., Dalton Trans. 1985, 731-735. doi:10.1039/DT9850000731

44. Hashmi, A. S. K.; Blanco, M. C.; Kurpejovic, E.; Frey, W.; Bats, J. W. Adv. Synth. Catal. 2006, 348, 709-713. doi:10.1002/adsc.200606012

45. Herb, C.; Maier, M. E. J. Org. Chem. 2003, 68, 8129-8135. doi:10.1021/jo035054g

\section{License and Terms}

This is an Open Access article under the terms of the Creative Commons Attribution License (http://creativecommons.org/licenses/by/2.0), which permits unrestricted use, distribution, and reproduction in any medium, provided the original work is properly cited.

The license is subject to the Beilstein Journal of Organic Chemistry terms and conditions:

(http://www.beilstein-journals.org/bjoc)

The definitive version of this article is the electronic one which can be found at: doi:10.3762/bjoc. 7.90 